\title{
The impact of GI events on persistence and adherence to osteoporosis treatment: 3-, 6-, and 12-month findings in the MUSIC-OS study
}

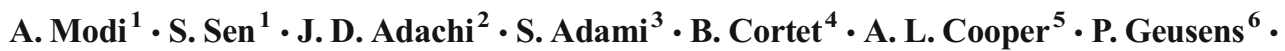 \\ D. Mellström ${ }^{7}$ - J. P. Weaver ${ }^{1}$ - J. P. van den Bergh ${ }^{6,8} \cdot$ P. Keown ${ }^{9}$ - S. Sajjan ${ }^{1}$
}

Received: 22 March 2017 / Accepted: 12 October 2017 / Published online: 6 November 2017

(C) The Author(s) 2017. This article is an open access publication

\begin{abstract}
Summary The goal of this multinational, prospective, observational study was to examine the relationship between gastrointestinal (GI) events and self-reported levels of medication adherence and persistence in postmenopausal women. A total of $73.9 \%$ of patients remained on their osteoporosis (OP) therapy at month 12 , although the presence of a GI event at baseline, month 3, and month 6 significantly reduced month 12 persistence among new users. The odds of a month- 12 ADEOS score $\geq 20$ were significantly lower among patients who experienced a GI event between baseline and month 6 . The occurrence of GI events was observed to be associated with a lower likelihood of patient adherence and persistence to OP medication.
\end{abstract}

Deceased (Dr. Adami, March 2016; Dr. Sajjan, December 2015)

A. Modi

ankita.modi@merck.com

1 Center for Observational and Real-World Evidence (CORE), Merck \& Co., Inc., 600 Corporate Drive, Mailstop: CRB-205, Kenilworth, NJ 07033, USA

2 St Joseph's Healthcare and McMaster University, Hamilton, ON, Canada

3 Department of Medicine, University of Verona, Verona, Italy

4 Department of Rheumatology, University Hospital of Lille, Lille Cedex, France

5 Bridge Medical Center, Crawley, West Sussex, UK

6 Department of Rheumatology, Maastricht University Medical Center, Maastricht, The Netherlands

7 Department of Internal Medicine and Geriatrics, Gothenburg University, Gothenburg, Sweden

8 Department of Internal Medicine, VieCuri Medical Center, Venlo, The Netherlands

9 Syreon Corporation, Vancouver, Canada
Introduction This study examines the relationship between gastrointestinal (GI) events and self-reported adherence and persistence with initial osteoporosis (OP) therapy over the course of the first 12 months of treatment.

Methods The Medication Use Patterns, Treatment Satisfaction, and Inadequate Control of Osteoporosis Study was a multinational, prospective, observational study examining the impact of GI events on OP management in postmenopausal women. Information regarding GI events was collected at the time of enrollment and at months 3, 6, and 12 of follow-up. Patients reported GI events and medication persistence and completed the 12-item Adherence Evaluation of Osteoporosis treatment (ADEOS) questionnaire. Multivariate logistic and general linear models examined the association between GI events at various time points and persistence and adherence at month 12 .

Results The study enrolled 2943 women; $22.8 \%$ were classified as new users of OP therapy and the remainder were considered experienced users. Across all patients, $68.1 \%$ reported GI events at baseline; by month 12 , over $80 \%$ of subjects who completed follow-up reported at least one GI problem. The majority of patients $(86.7 \%)$ were treated only with bisphosphonates at baseline. At month 12,73.9\% of patients remained on therapy; logistic regression revealed that those with GI problems by month 6 were significantly less likely to persist with treatment, after adjusting for other factors. The odds of a month 12 ADEOS score $\geq 20$ (considered predictive of adherence) were significantly lower among patients who experienced a GI event between baseline and month 6 .

Conclusions The occurrence of GI events was associated with a lower likelihood of patient adherence to and persistence with OP medication.

Keywords Adherence · Gastrointestinal events ·

Medication $\cdot$ Osteoporosis $\cdot$ Persistence 


\section{Introduction}

Among women, accelerated bone loss during the period postmenopause increases the risk of osteoporosis (OP)-related fractures [1]. In the EU alone, an estimated 2.3 million women experienced an incident fracture in 2010 and the number is projected to rise by $25 \%$ by 2025 [2]. Several treatments with demonstrated antifracture efficacy have been developed over the last two decades. However, poor levels of treatment persistence (continuation of therapy), adherence (filling prescriptions on time), and compliance (taking medications as prescribed) in clinical practice pose significant challenges to effective fracture risk reduction strategies [3-5]. Among patients initiating OP treatment, typically only 20$60 \%$ are persistent with treatment in the first year of therapy, and the rate declines in subsequent years [6-12]. Similarly, adherence to and compliance with therapy is suboptimal; approximately 40 $60 \%$ of patients are adherent to treatment in the first year [13-15].

Several factors have been linked to poor compliance with and adherence/persistence with OP therapy. Dissatisfaction with treatment and the patient experience with or fear of treatment of side effects may influence some patients to transition to other medications or discontinue therapy [16-18]. There is also a growing body of evidence suggesting a relationship between gastrointestinal (GI) events and a lack of consistent and persistent use of OP therapy. GI events that occur prior to and while on treatment have been linked with early treatment discontinuation and worse adherence [9, 19-22].

The Medication Use Patterns, Treatment Satisfaction, and Inadequate Control of Osteoporosis Study (MUSIC-OS) is an observational study of postmenopausal women diagnosed with OP in the EU and Canada. Nearly $70 \%$ of participants on or initiating OP treatment reported GI events within 6 months prior to study entry [23]. GI events that occurred during the baseline period were associated with lower treatment satisfaction and adherence among experienced users and lower health-related quality of life (HRQoL) among both new and experienced users. The current analysis sought to examine the relationship between GI events and subjects' self-reported levels of medication adherence/compliance to and persistence with initial therapy over the course of the first 12 months of the MUSIC-OS study.

\section{Methods}

\section{Study design and subjects}

The design of the MUSIC-OS and the characteristics of the patients enrolled have been previously described [24]. In general, MUSIC-OS investigators recruited sequential postmenopausal women aged 55 and older with a physician diagnosis of OP from 96 health clinics representing both primary care $(n=56)$ and specialty clinics $(n=40)$ in the EU and Canada. In Sweden and Italy, participating centers were primarily specialty clinics; while in France, the UK, and Canada, they were principally primary care practices. A total of 3335 participants were enrolled between March 2012 and June 2013, and 2980 were protocol-eligible patients and currently receiving or initiating oral pharmacologic OP treatment. For this study, oral pharmacologic OP treatment included bisphosphonates (BIS) (alendronate, risedronate, ibandronate), strontium ranelate, selective estrogen receptor modulators (SERMs [e.g., raloxifene]), and bazedoxifene. Six patients additionally received calcitonin. Calcium, vitamin D, and estrogen and other hormone replacement therapies were not considered pharmacologic treatments. The study was performed in accordance with the Declaration of Helsinki and either the local ethics board or a central institutional review board. All participants provided written informed consent prior to enrollment.

The study contained two cohorts of participants defined by treatment status. New users were defined as subjects who initiated oral pharmacologic therapy at enrollment or who were receiving oral pharmacological therapy for less than 3 months prior to enrollment with no previous history of any OP pharmacological therapy. Subjects receiving the same oral pharmacological therapy for at least 3 months continuously prior to enrollment and at the time of enrollment were considered to be experienced users. Additionally, each cohort was further categorized by the presence or absence of participantreported GI events at baseline, month 3, month 6 , and month 12. Patients reported their GI problems using a specified list of events that were categorized as upper GI (heartburn/acid reflux, upset stomach/indigestion, nausea/vomiting, pain behind the breastbone, pain or difficulty swallowing, stomach pain above the navel) or lower GI (diarrhea or constipation, stomach pain below the navel, bloating).

\section{Measures}

Baseline information was captured at the enrollment visit. Data for months 3,6, and 12 were collected by a hard copy questionnaire that was mailed to participants. GI events during baseline were identified as those that occurred during the 6-month period prior to enrollment. Month $3 \mathrm{GI}$ events encompassed those that occurred through the first 3 months of the study, while month 6 GI events were captured after month 3 through month 6 , and month 12 GI events were captured after month 6 through month 12 .

Persistence was defined as continuing with original therapy without switch or discontinuation. At months 3 and 6, persistence was determined by asking the patient if they had discontinued or switched their OP treatment in the previous 3 months; month 12 persistence was determined by asking the patient if they had discontinued or switched in the previous 6 months.

Participants also completed the 12-item Adherence Evaluation of Osteoporosis treatment (ADEOS) questionnaire, which is a patient-reported measure specifically designed for osteoporotic women that attempts to capture beliefs and perceptions regarding 
OP medications and how compliant or adherent women are to their prescribed therapy [25]. Scores calculated from the ADEOS questionnaire range from 0 to 22 , with scores $\geq 20$ considered to be predictive of medication adherence and scores $\leq 16$ predictive of treatment discontinuation in the following period. In the current study, a score $\geq 20$ was the threshold used to determine adherence in logistic regression analysis.

\section{Statistical analysis}

The count and proportion of participants experiencing GI events was calculated. At baseline, patients were stratified by user status (new vs experienced) and the type of GI event (upper vs lower). For GI events at months 3, 6, and 12, patients were stratified by baseline user status (new vs experienced).

The association between GI events and persistence was modeled by logistic regression. To examine the association between GI events and ADEOS scores, logistic regression and general linear models were employed. The reference group for all comparisons consisted of participants with no GI events either at baseline or throughout the period of analysis (month 3, month 6 , or month 12). Modeling was conducted in two phases. In the first phase, a full model was run, adjusted for patient demographic and clinical characteristics at enrolment (age, body mass index [BMI]), duration of OP, duration of treatment for OP, comorbidities (including cardiac, endocrine, and GI disorders, metabolic and nutrition disorders, musculoskeletal diseases, vascular disorders, and malignant or benign neoplasms), concurrent medications, history of falls and fractures, predominant OP treatment, and occurrence of previous GI events, and included all participants for whom these variables were reported. The full model was reduced during the second phase using backward elimination, where variables were retained if their $p$ value was $\leq 0.15$.

\section{Results}

\section{Identification of eligible participants}

Of the 3334 patients enrolled, 3256 remained eligible after exclusions and 2964 were treated. Of these, 2943 completed the GI symptom report for baseline and were split into new users (672 patients, $22.8 \%$ ) and experienced users (2271 patients, $77.2 \%$ ). The majority of patients remained eligible and completed followup questionnaires for the duration of the study (Fig. 1).

\section{Frequency of GI events}

At baseline, $68.1 \%$ of patients reported GI problems, with slightly more experienced users $(69.2 \%)$ reporting GI problems than new users $(64.6 \%)$. This varied by country, ranging from $57.8 \%$ (the Netherlands) to $75.6 \%$ (UK, data not shown). New cases of GI problems were reported at each time period
(7.6\% at month 3, 3.6\% at month $6,2.1 \%$ at month 12 ), and by month 12 , over $80 \%$ of participants with completed questionnaires had reported at least one GI problem ( $81.5 \%$ of new users, $81.1 \%$ of experienced users; Fig. 2). Among those experiencing GI events at months 3, 6, and 12, 77 to $80 \%$ experienced upper GI problems while 74 to $76 \%$ experienced lower GI problems. Among patients reporting GI events at baseline, $11.7 \%$ of new users and $23.4 \%$ of experienced users reported using GI medications in the previous 12 months.

\section{Falls and fractures}

Patterns of falls and fractures among OP patients were reported at baseline and at each follow-up period. Among new users, falls were more common during the study $(46.9 \%$ had at least one fall between baseline and month 12) than during the 12 months prior to study enrollment (37.4\%). It is possible that the difference in frequency may reflect recall bias during the pre-study period, since minor falls may not be highly memorable, but the data do not allow us to explore this further. A total of $49.4 \%$ of new users reported a prior OP-related fracture at baseline, but only $0.8 \%$ experienced a fracture between baseline and month 12. These patterns were also observed among experienced users: falls prior to study enrollment occurred in only $21.4 \%$ of experienced users, but $38.0 \%$ fell at least once by month 12 . And while almost half $(49.5 \%)$ of experienced users reported an OP-related fracture prior to the study, only $2.1 \%$ experienced a fracture during the study period.

\section{Osteoporosis treatment}

The majority of patients $(86.7 \%)$ were treated only with BIS at baseline. Among these patients, baseline GI events were more common among experienced users than new users (69.7 vs $63.3 \%, p=0.004$ ). However, new users of BIS at baseline experienced significantly more GI problems over the 12month follow-up period than experienced users. The incidence of GI problems (for those without existing GI problems) at months 3, 6, and 12 for new users of BIS was 28.8, 41.1, and $46.1 \%$, respectively, while for experienced users, those values were $21.1,31.2$, and $37.1 \%$, respectively (all $p<0.05)$. Among the much smaller number of patients treated at baseline with non-BIS therapy $(n=343)$, baseline GI events were more common in new users than in experienced users though this difference was not statistically significant ( 79.6 vs $67.7 \%, p=0.131$ ). This difference was evident throughout the 12-month follow-up period. The incidence of GI problems (for those without existing GI problems) at months 3, 6, and 12 for experienced users of non-BIS therapy was 20.0, 26.3, and $33.7 \%$, and for new users these values were 10.0, 20.0, and $20.0 \%$ (data not shown). However, the number of patients in these groups was small, and none of the differences reached statistical significance. 
Fig. 1 Patient selection. ${ }^{1}$ Analytical severity code 2 : Include in Enroll Population and Exclude from Eligible Population. ${ }^{2}$ This includes 16 participants excluded for protocol violations postbaseline report.

${ }^{3}$ Those without baseline GI status indicate either the baseline assessment was not completed or it was partially completed with a combination of "No" GI problems and missing responses. ${ }^{4}$ Eligible users are those who completed a questionnaire at this time period with no missing responses

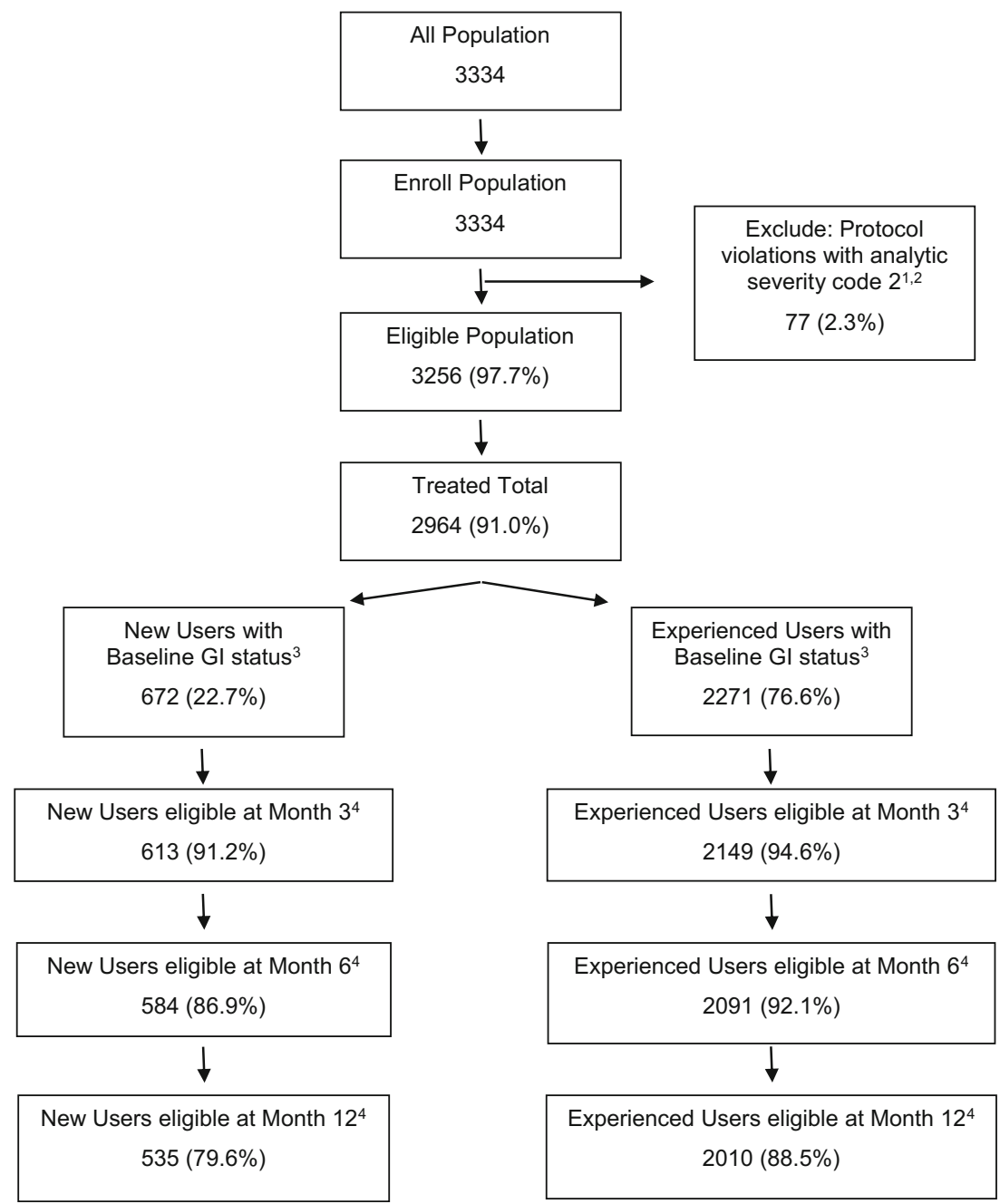

\section{Persistence}

Over one fourth of patients (26.1\%) discontinued or switched treatment by month 12 . Experienced users were more likely to continue therapy (76.1\%) compared with new users (66.7\%). Persistence was similar between those with and without baseline GI problems, but new users with baseline GI problems were the most likely to discontinue therapy (Fig. 3). Overall,

Fig. 2 Cumulative incidence of GI events. B, baseline; M3, month 3; M6, month 6; M12, month 12

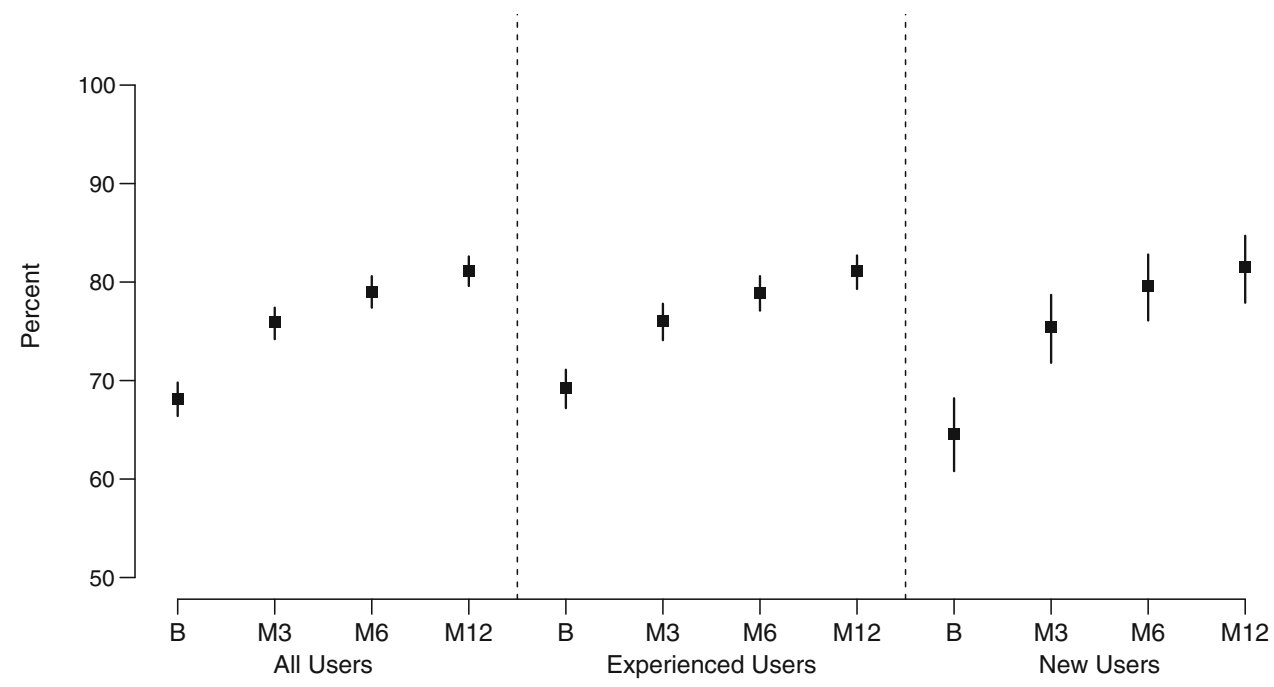


Fig. 3 Probability of continuing with original osteoporosis medication by the treatment group and presence of GI problems at baseline

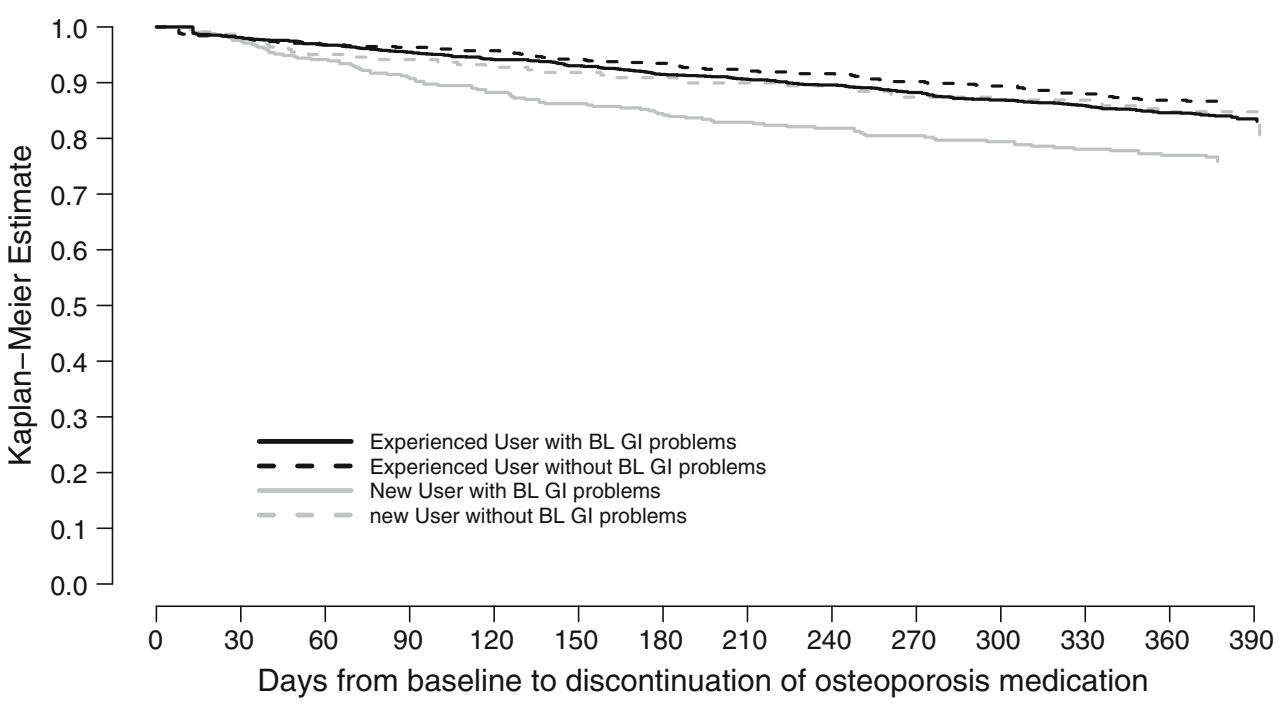

persistence at month 12 was higher for those treated with only BIS at baseline $(76.2 \%)$ than for those treated with non-BIS $(66.8 \%)$. As with the overall cohort, persistence was higher among experienced users than new users in both subgroups, although the difference in persistence between new and experienced users was numerically smaller $(6.1 \%)$ among BIStreated subjects $(71.0$ vs $77.1 \%)$ than among non-BIStreated subjects $(14.4 \%$ ) (53.6 vs $68.0 \%)$.

Logistic regression showed that while GI events at baseline were not significantly associated with persistence at month 12 , patients with GI problems by month 6 were $39 \%$ less likely to persist with treatment at month 12 (odds ratio $[\mathrm{OR}]=0.61$, $95 \%$ confidence interval $[\mathrm{CI}]=[0.47,0.80], p=0.0003$, Table 1). Additionally, new users had a $48 \%$ lower odds of persisting with treatment by month 12 than did experienced users $(\mathrm{OR}=0.52,95 \% \mathrm{CI}=[0.35,0.77], p=0.0001)$. Compared with those treated with only BIS at baseline, those treated with only non-BIS had a $56 \%$ lower odds of month 12 persistence $(\mathrm{OR}=0.44,95 \% \mathrm{CI}=[0.33,0.59], p<0.001)$. Other significant factors associated with lower odds of persistence included low BMI (OR for BMI $<18.5$ vs BMI of 18.5 to $24.99=0.37,95 \% \mathrm{CI}=[0.23,0.59], p<0.0001)$ and $\mathrm{a}$ longer duration of OP (OR for 5-10 years vs $<1$ year $=0.61$, $95 \% \mathrm{CI}=[0.41,0.89], p=0.0112$; OR for $>10$ years vs $<1$ year $=0.61,95 \% \mathrm{CI}=[0.41,0.91], p=0.0143)$.

\section{ADEOS scores}

Among those who remained in the study at 12 months, $93.4 \%$ completed the ADEOS questionnaire, including $90.6 \%$ of new users and $94.1 \%$ of experienced users. For new users, the mean (SD) ADEOS total score was 17.8 (3.19) at baseline. Mean (SD) total score increased slightly at month 3 to 18.8 (2.95) and maintained at 18.8 (3.00) at month 12 , with similar scores for those with and without baseline GI problems (18.5 vs 19.3). ADEOS scores $\geq 20$ were reported for $45.7 \%$ of new users with baseline GI problems and $61.7 \%$ of new users without baseline GI problems. Experienced users reported mean ADEOS total scores that were stable at all three time points (18.9 at baseline, 18.9 at month 3 , and 18.7 at month 12). ADEOS scores $\geq 20$ were reported for $45.5 \%$ of patients who had baseline GI problems and $53.3 \%$ of those without baseline GI problems.

Multivariate regression revealed that for the overall population, there was no statistically significant difference in ADEOS total scores at month 12 between participants that had a GI event at baseline and those that did not. However, events that occurred throughout the study had a more important effect, and those with a GI event between baseline and month 12 had a significantly lower ADEOS total score at month 12 (least-squares [LS] mean difference $=-0.72,95 \%$ $\mathrm{CI}=[-1.03,-0.42], p<0.0001$, Table 2). Additionally, obese patients, those with falls either after enrollment or both before and after enrollment, and those with comorbidities at baseline had lower month 12 ADEOS total scores. From logistic regression, participants that reported a GI event at baseline $(\mathrm{OR}=0.77 ; 95 \% \mathrm{CI}=[0.63-0.96], p=0.0166)$ and from baseline to month $12(\mathrm{OR}=0.72,95 \% \mathrm{CI}=[0.59-0.89]$, $p=0.0023$ ) were significantly less likely to report ADEOS scores $\geq 20$ compared with those who did not report experiencing a GI event before or during the study period. A disease duration of 1 to 5 years (vs $<1$ year) and a history of falls either after enrollment or both before and after enrollment also reduced the odds of reporting an ADEOS score $\geq 20$ at month 12. Factors that increased the odds of an ADEOS score $\geq 20$ included older age (70 years or older) and concurrent medications at baseline. Patients receiving treatment predominantly with non-bisphosphonates had lower mean ADEOS scores (LS mean difference $=-0.29,95 \% \mathrm{CI}=[-0.676,0.088]$, $p=0.1318)$ and a reduced odds of reporting an ADEOS score $\geq 20(\mathrm{OR}=0.78,95 \%$ [CI $=0.599,1.020], p=0.0701)$, though neither of these trends reached statistical significance. 
Table 1 Multivariate logistic regression analysis of patientreported persistence with initial OP treatment at month 12

\begin{tabular}{|c|c|c|c|}
\hline & \multicolumn{3}{|c|}{ Logistic regression } \\
\hline & Odds ratio $^{\mathrm{a}}$ & $95 \% \mathrm{CI}$ & $p$ value \\
\hline \multicolumn{4}{|l|}{ GI problems (reference $=$ no GI event ever) } \\
\hline Baseline GI problems & 0.90 & $(0.69,1.18)$ & 0.4515 \\
\hline GI event between baseline and month 6 & 0.61 & $(0.47,0.80)$ & 0.0003 \\
\hline New users vs experienced users (reference) & 0.52 & $(0.35,0.77)$ & 0.0001 \\
\hline \multicolumn{4}{|l|}{ BMI $($ reference $=$ normal $18.50-24.99)$} \\
\hline $\mathrm{BMI} \geq 30$ & 0.92 & $(0.67,1.28)$ & 0.6361 \\
\hline BMI 25.00 to 29.99 & 1.06 & $(0.83,1.35)$ & 0.6530 \\
\hline $\mathrm{BMI}<18.50$ & 0.37 & $(0.23,0.59)$ & $<0.0001$ \\
\hline \multicolumn{4}{|c|}{ Duration of OP at baseline (reference $=<1$ year) } \\
\hline $1-5$ years & 0.84 & $(0.58,1.22)$ & 0.3618 \\
\hline $5-10$ years & 0.61 & $(0.41,0.89)$ & 0.0112 \\
\hline$>10$ years & 0.61 & $(0.41,0.91)$ & 0.0143 \\
\hline \multicolumn{4}{|l|}{ Baseline treatment (reference = BIS only) } \\
\hline No medication & 0.86 & $(0.56,1.31)$ & 0.4719 \\
\hline Non-BIS only & 0.44 & $(0.33,0.59)$ & $<0.0001$ \\
\hline BIS and non-BIS & 1.22 & $(0.35,4.26)$ & 0.7554 \\
\hline
\end{tabular}

$B I S$, bisphosphonate; $B M I$, body mass index; $C I$, confidence interval; $G I$, gastrointestinal; $O P$, osteoporosis

${ }^{\text {a }}$ Odds of continuing treatment

\section{Discussion}

In this study, the large majority of participants reported GI events at baseline, and there were 7.6, 3.6, and $2.1 \%$ of new GI cases at months 3,6 , and 12 , respectively. Participants with either baseline or newly occurring GI events had a higher risk of discontinuation and lower odds of an ADEOS score of $\geq 20$ by month 12 compared with participants who never reported a GI event. Specifically, the risk of OP treatment discontinuation at month 12 was 38\% higher among new users who reported a baseline GI event and 75\% higher among new users who reported a GI event by month 6 .

The frequency of GI events observed in this study was somewhat higher than that in previously published studies. In the POSSIBLE-US study, GI events were present in about $20 \%$ of subjects at study entry and rose to $31 \%$ among new users and $26 \%$ at month 6 among stable users, with slightly lower percentages ( $27 \%$ of new users and $22 \%$ of stable users) at month 12 [20]. The higher rate of GI events in our study may be attributable to the length of look-back period at baseline, which was 6 months compared with "at study entry" in POSSIBLE-US. Additionally, in the current study, the questionnaire used was specifically inquiring about GI events; while in clinical practice, providers may ask more generally about overall adverse events. The age of the patient population in this study was also older than that of those typically followed in dyspepsia studies. However, even though the frequency of GI events observed in the current study was higher than that in POSSIBLE-US, both studies demonstrate that participant- reported GI events are common among women initiating or continuing $\mathrm{OP}$ treatment and are associated with early discontinuation of initial therapy.

It should be noted that GI events were self-reported and may not have resulted in a medical encounter. For example, heartburn and stomach upset were the most common types of upper GI events reported. These may often be treated with over-the-counter medications and therefore may not come to the attention of clinicians. Our results indicate that GI events, whether or not they required medical intervention, influence persistence and adherence to treatment. Further, they demonstrate the need for clinicians to proactively query patients on OP treatment regarding GI complaints to minimize treatment discontinuation and promote good adherence with treatment to achieve the overarching goal of fracture prevention.

In the current study, $73.9 \%$ of patients remained on their OP therapy at month 12 , although the presence of a GI event at baseline, month 3 , and month 6 significantly reduced month 12 persistence among new users. The POSSIBLE-US study reported a probability of persistence at 1 year of $66 \%$ [18], and that patient-reported GI events at the time of study entry were associated with a $30 \%$ higher risk of treatment discontinuation at month 12 of the study [20]. In addition, side effects that patients attribute to OP treatment while on therapy have also been found to predict discontinuation at 1 year [18]. Participants in our study who reported GI events at month 3 but not at baseline may have attributed these events to their OP therapy, although a cause and effect relationship cannot be 
Table 2 Multivariate logistic regression and general linear model analyses of ADEOS scores at month 12

\begin{tabular}{|c|c|c|c|c|c|c|}
\hline & \multicolumn{3}{|c|}{ Logistic regression } & \multicolumn{3}{|c|}{ General linear model } \\
\hline & Odds ratio $^{\mathrm{a}}$ & $95 \% \mathrm{CI}$ & $p$ value & $\begin{array}{l}\text { LS mean } \\
\text { difference }\end{array}$ & $95 \%$ CI & $p$ value \\
\hline \multicolumn{7}{|l|}{ GI problems (reference $=$ no GI event ever) } \\
\hline Baseline GI problems & 0.77 & $(0.63,0.96)$ & 0.0166 & -0.18 & $(-0.49,0.12)$ & 0.2340 \\
\hline GI event between baseline and month 12 & 0.72 & $(0.59,0.89)$ & 0.0023 & -0.72 & $(-1.03,-0.42)$ & $<0.0001$ \\
\hline New users vs experienced users (reference) & 1.07 & $(0.81,1.40)$ & 0.6392 & 0.11 & $(-0.29,0.51)$ & 0.5866 \\
\hline \multicolumn{7}{|l|}{$\begin{array}{l}\text { Age group at baseline } \\
\quad \text { (reference }=50-60 \text { years })\end{array}$} \\
\hline $60-70$ years & 1.24 & $(0.96,1.60)$ & 0.1067 & - & - & - \\
\hline $70-80$ years & 1.31 & $(1.01,1.71)$ & 0.0445 & - & - & - \\
\hline$\geq 80$ years & 1.43 & $(1.04,1.96)$ & 0.0270 & - & - & - \\
\hline \multicolumn{7}{|l|}{ BMI $($ reference $=$ normal $18.50-24.99)$} \\
\hline $\mathrm{BMI} \geq 30$ & - & - & - & -0.47 & $(-0.85,-0.10)$ & 0.0137 \\
\hline BMI 25.00 to 29.99 & - & - & - & -0.02 & $(-0.30,0.26)$ & 0.8984 \\
\hline $\mathrm{BMI}<18.50$ & - & - & - & 0.44 & $(-0.27,1.16)$ & 0.2217 \\
\hline \multicolumn{7}{|l|}{$\begin{array}{l}\text { Duration of OP at baseline } \\
\quad \text { (reference }=<1 \text { year })\end{array}$} \\
\hline $1-5$ years & 0.71 & $(0.54,0.94)$ & 0.0179 & 0.32 & $(-0.15,0.79)$ & 0.1802 \\
\hline $5-10$ years & 1.00 & $(0.74,1.35)$ & 0.9989 & -0.21 & $(-0.23,0.66)$ & 0.3441 \\
\hline$>10$ years & 0.99 & $(0.72,1.37)$ & 0.9646 & -0.33 & $(-0.75,0.08)$ & 0.1116 \\
\hline \multicolumn{7}{|l|}{$\begin{array}{l}\text { History of falls by month } 12 \\
\quad \text { (reference }=\text { no falls })\end{array}$} \\
\hline After enrollment & 0.73 & $(0.58,0.92)$ & 0.0090 & -0.12 & $(-0.472,0.232)$ & 0.5037 \\
\hline Before enrollment & 0.85 & $(0.67,1.08)$ & 0.1783 & -0.48 & $(-0.83,-0.14)$ & 0.0060 \\
\hline Both & 0.70 & $(0.52,0.94)$ & 0.0198 & -0.57 & $(-1.01,-0.13)$ & 0.0108 \\
\hline $\begin{array}{l}\text { Concurrent medication at baseline } \\
\quad(\text { reference }=\text { no })\end{array}$ & 1.37 & $(1.11,1.70)$ & 0.0040 & 0.64 & $(0.32,0.95)$ & 0.0001 \\
\hline Comorbidities at baseline $($ reference $=$ no $)$ & - & - & - & -0.25 & $(-0.50,-0.003)$ & 0.0473 \\
\hline
\end{tabular}

$L S$, least-squares difference in mean ADEOS scores between groups; $O P$, osteoporosis; $B M I$, body mass index; $C I$, confidence interval; $G I$, gastrointestinal

${ }^{\text {a }}$ Odds of ADEOS score $\geq 20$

ascertained in this observational study. GI medication use [26, $27]$ and GI events resulting in medical service claims while on therapy $[21,26,27]$ have also demonstrated a higher risk of treatment discontinuation. Our results, coupled with results from previous studies, indicate that GI events, whether present at baseline or newly occurring, are associated with higher risk of initial therapy discontinuation.

The occurrence of GI events among patients in our study were associated with lower odds of adherence to treatment and lower adherence scores as measured by ADEOS $<20$ among participants with GI events that occurred after baseline. The mean ADEOS scores were 18.2 (out of 22), which are similar to mean scores in the ADEOS validation study of patients on oral OP treatment [25]. Although the difference in mean ADEOS scores between GI and non-GI cohorts was modest, the difference was significant, indicating that GI events appear to provide a signal of treatment non-compliance.
There are limitations to this study that should be noted. First, self-selection bias among investigators and participants who chose to participate may have yielded a more actively managed sample of participants who were also more engaged in their health. Discontinuation of the initial OP therapy and the occurrence of GI events were participant-reported and may be subject to recall bias. Additionally, the severity of GI events experienced cannot be ascertained. This study examined the association between GI events and study outcomes, but it would be inappropriate to infer causation. Finally, while outcomes were adjusted for multiple patient characteristics, there may have been other unmeasured factors which influenced the results.

The results of this study further the understanding of the impact of GI events on lower levels of adherence and persistence to OP therapy among postmenopausal women. Additional study is warranted to examine the mechanisms 
driving these behaviors and to establish strategies to improve patient compliance with OP medication.

Acknowledgements The authors thank the following site investigators for their participation in the study. In Canada, Aliya Khan, Bradley Schweitzer, Kevin Saunders, Miranda Du Preez, Kenneth Bayly, Tersia Lichtenstein, Richard Boroditsky, John S. Corey, Jay Sinha, Jack Kooy, Arun Nayar, Suzanne Arndt, Iman Mohamed, and Wojciech P. Olszynski. In France, Isabelle Legroux, Sandrine Malochet Guinamand, Marie Christine De Vernejoul, Christian Roux, Eric Thomas, Patrice Fardellone, Florence Lévy-Weil, Corina Ursu, Francois Barucq, Olivier Bisch, Philippe Bouche, Nicolas Breton, François Lacoin, Georgios Makridis, Philippe Marmor, Marcel Ruetsch, Denis Taminau, Michel Bismuth, Michel Bourgoin, Didier Sacareau, Christian Scellier, Jean-Louis Wurtz, Stephane Le Mouel, Claude Bortolotti, Bernard Lauer, Hervé Amar, and Didier Cadinot. In Italy, Giorgio Gandolini, Mario Barbagallo, Ranuccio Nuti, Marco Di Monaco, Gloria Bonaccorsi, Sandro Giannini, Antonio Del Puente, Salvatore Minisola, Umberto Tarantino, Maria Luisa Brandi, Ombretta Di Munno, Giovanni Mario D'Avola, Maurizio Caminiti, Bruno Frediani, Claudio Marcocci, Franco Grimaldi, Paolo Falaschi, Mario Biondi, Giulia Letizia Mauro, Francesco Paolo Cantatore, and Maurizio Muratore. In Sweden, Karl-Goran Thorngren and Kristina Akesson. In the Netherlands, M. den Heijer, Neveen A. T. Hamdy, H. R. Franke, Ton Boermans, Adriaan Kooy, and Nicolaas K. Valk. In the UK, Patrick Eavis, Robert Brownlie, Jon Brunskill, Michael Gumbley, Richard Gaunt, Jennifer Litchfield, G. D. Martin, Boo McConnell, Terry McCormack, Narayanan Annamalai, Devi Srinivasan, Amrit Takhar, Trevor Gooding, Paul Conn, Ian Parker, Michael Redmond, John Calvert, T. W. S. Cookson, Paul Ainsworth, Amardeep Heer, and Nell Wyatt.

Funding information The study was funded by Merck \& Co., Inc.

Compliance with ethical standards The study was performed in accordance with the Declaration of Helsinki and either the local ethics board or a central institutional review board. All participants provided written informed consent prior to enrollment.

Conflicts of interest A. Modi and S. Sen are employees of Merck \& Co., Inc. and own stock in the company. J.D. Adachi has received grant support and speaker honorarium from Actavis, Amgen, Eli Lilly, Merck \& Co., Inc. and Novartis. J.D. Adachi is a consultant for Amgen, Eli Lilly, and Merck \& Co., Inc. S. Adami has received consulting honorarium from Merck \& Co., Inc. and served as a board member for Merck \& Co., Inc. B. Cortet has received research grants, consulting honorarium, and/or speaker honorarium from Amgen, Expanscience, Ferring, Eli Lilly, Merck \& Co., Inc., Merck Sharp \& Dohme, Medtronic, and Roche diagnostics. A.L. Cooper has received research grants, advisory board and/or speaker honorarium from Consilient Health and Internis Pharmaceuticals. P. Geusens has received research grants, advisory board and/or speaker honorarium from Pfizer, Abbott, Eli Lilly, Amgen, Merck Sharp \& Dohme, Will Pharma, Roche, UCB pharmaceuticals, BristolMyers Squibb, and Novaritis. D.Mellström has received consulting honorarium from Merck Sharp \& Dohme. J.P. Weaver is an employee of Merck \& Co., Inc. J.P. van den Bergh is a paid consultant at Amgen and Will Pharma. J.P. van den Bergh has received research grants and speaker honorarium from Amgen, Will Pharma, and Eli Lilly. P.A. Keown is the director of and employed by Syreon Corporation and has received financial remuneration from Merck \& Co., Inc. to conduct the study, participate in study meetings, and perform statistical analysis. S. Sajjan was an employee of Merck \& Co., Inc. and owned stock in the company at the time of the study.
Open Access This article is distributed under the terms of the Creative Commons Attribution-NonCommercial 4.0 International License (http:// creativecommons.org/licenses/by-nc/4.0/), which permits any noncommercial use, distribution, and reproduction in any medium, provided you give appropriate credit to the original author(s) and the source, provide a link to the Creative Commons license, and indicate if changes were made.

\section{References}

1. Finkelstein JS, Brockwell SE, Mehta V et al (2008) Bone mineral density changes during the menopause transition in a multiethnic cohort of women. J Clin Endocrinol Metab 93:861-868

2. Hernlund E, Svedbom A, Ivergard M, Compston J, Cooper C, Stenmark J, McCloskey EV, Jonsson B, Kanis JA (2013) Osteoporosis in the European Union: medical management, epidemiology and economic burden. A report prepared in collaboration with the International Osteoporosis Foundation (IOF) and the European Federation of Pharmaceutical Industry Associations (EFPIA). Arch Osteoporos 8:136

3. Cotte FE, Mercier F, De Pouvourville G (2008) Relationship between compliance and persistence with osteoporosis medications and fracture risk in primary health care in France: a retrospective case-control analysis. Clin Ther 30:2410-2422

4. Gold DT, Martin BC, Frytak JR, Amonkar MM, Cosman F (2007) A claims database analysis of persistence with alendronate therapy and fracture risk in post-menopausal women with osteoporosis. Curr Med Res Opin 23:585-594

5. Siris ES, Harris ST, Rosen CJ, Barr CE, Arvesen JN, Abbott TA, Silverman S (2006) Adherence to bisphosphonate therapy and fracture rates in osteoporotic women: relationship to vertebral and nonvertebral fractures from 2 US claims databases. Mayo Clinic Proc 81:1013-1022

6. Balasubramanian A, Brookhart MA, Goli V, Critchlow CW (2013) Discontinuation and reinitiation patterns of osteoporosis treatment among commercially insured postmenopausal women. Int J Gen Med 6:839-848

7. Gallagher AM, Rietbrock S, Olson M, van Staa TP (2008) Fracture outcomes related to persistence and compliance with oral bisphosphonates. J Bone Miner Res 23:1569-1575

8. Hadji P, Claus V, Ziller V, Intorcia M, Kostev K, Steinle T (2012) GRAND: the German retrospective cohort analysis on compliance and persistence and the associated risk of fractures in osteoporotic women treated with oral bisphosphonates. Osteoporos Int 23:223-231

9. Lo JC, Pressman AR, Omar MA, Ettinger B (2006) Persistence with weekly alendronate therapy among postmenopausal women. Osteoporos Int 17:922-928

10. Siris ES (2009) Clinical issues with bisphosphonate therapy for osteoporosis. Introduction. Am J Med 122:S1-S2

11. van den Boogaard $\mathrm{CH}$, Breekveldt-Postma NS, Borggreve SE, Goettsch WG, Herings RM (2006) Persistent bisphosphonate use and the risk of osteoporotic fractures in clinical practice: a database analysis study. Curr Med Res Opin 22:1757-1764

12. Ziller V, Kostev K, Kyvernitakis I, Boeckhoff J, Hadji P (2012) Persistence and compliance of medications used in the treatment of osteoporosis - analysis using a large scale, representative, longitudinal German database. Int J Clin Pharmacol Ther 50:315-322

13. Cramer JA, Lynch NO, Gaudin AF, Walker M, Cowell W (2006) The effect of dosing frequency on compliance and persistence with bisphosphonate therapy in postmenopausal women: a comparison of studies in the United States, the United Kingdom, and France. Clin Ther 28:1686-1694 
14. Wade SW, Curtis JR, Yu J, White J, Stolshek BS, Merinar C, Balasubramanian A, Kallich JD, Adams JL, Viswanathan HN (2012) Medication adherence and fracture risk among patients on bisphosphonate therapy in a large United States health plan. Bone 50:870-875

15. Briesacher BA, Andrade SE, Yood RA, Kahler KH (2007) Consequences of poor compliance with bisphosphonates. Bone 41:882-887

16. Carr AJ, Thompson PW, Cooper C (2006) Factors associated with adherence and persistence to bisphosphonate therapy in osteoporosis: a cross-sectional survey. Osteoporos Int 17:1638-1644

17. McHorney CA, Spain CV (2011) Frequency of and reasons for medication non-fulfillment and non-persistence among American adults with chronic disease in 2008. Health Expect 14:307-320

18. Tosteson AN, Do TP, Wade SW, Anthony MS, Downs RW (2010) Persistence and switching patterns among women with varied osteoporosis medication histories: 12-month results from POSSIBLE US. Osteoporos Int 21:1769-1780

19. Reynolds K, Viswanathan HN, O'Malley CD et al (2012) Psychometric properties of the Osteoporosis-specific Morisky Medication Adherence Scale in postmenopausal women with osteoporosis newly treated with bisphosphonates. Ann Pharmacother 46:659-670

20. Woo C, Gao G, Wade S, Hochberg MC (2010) Gastrointestinal side effects in postmenopausal women using osteoporosis therapy: 1year findings in the POSSIBLE US study. Curr Med Res Opin 26:1003-1009

21. Yun H, Curtis JR, Guo L et al (2014) Patterns and predictors of osteoporosis medication discontinuation and switching among Medicare beneficiaries. BMC Musculoskelet Disord 15:112
22. Turbi C, Herrero-Beaumont G, Acebes JC, Torrijos A, Grana J, Miguelez R, Sacristan J, Marin F (2004) Compliance and satisfaction with raloxifene versus alendronate for the treatment of postmenopausal osteoporosis in clinical practice: an open-label, prospective, nonrandomized, observational study. Clin Ther 26: 245-256

23. Modi A, Sen S, Adachi JD et al (2016) Gastrointestinal symptoms and association with medication use patterns, adherence, treatment satisfaction, quality of life, and resource use in osteoporosis: baseline results of the MUSIC-OS study. Osteoporos Int 27:1227-1238

24. Modi A, Sen S, Adachi JD et al (2015) Rationale and design of MUSIC OS-EU: an international observational study of the treatment of postmenopausal women for osteoporosis in Europe and Canada. Clin Exp Rheumatol 33:537-544

25. Breuil V, Cortet B, Cotte FE, Arnould B, Dias-Barbosa C, Gaudin AF, Regnault A, Roborel de Climens A, Legrand E (2012) Validation of the adherence evaluation of osteoporosis treatment (ADEOS) questionnaire for osteoporotic post-menopausal women. Osteoporos Int 23:445-455

26. Penning-van Beest FJ, Goettsch WG, Erkens JA, Herings RM (2006) Determinants of persistence with bisphosphonates: a study in women with postmenopausal osteoporosis. Clin Ther 28:236-242

27. Rossini M, Bianchi G, Di Munno O, Giannini S, Minisola S, Sinigaglia L, Adami S, Treatment of Osteoporosis in clinical Practice Study G (2006) Determinants of adherence to osteoporosis treatment in clinical practice. Osteoporos Int 17:914-921 